\title{
Gamma-delta $(\gamma \delta)$ T cells: friend or foe in cancer development?
}

\author{
Yijing Zhao, Chao Niu and Jiuwei Cui
}

\begin{abstract}
Background: $\gamma \delta$ T cells are a distinct subgroup of T cells containing T cell receptors (TCRs) $\gamma$ and TCR $\delta$ chains with diverse structural and functional heterogeneity. As a bridge between the innate and adaptive immune systems, $\gamma \delta T$ cells participate in various immune responses during cancer progression. Because of their direct/indirect antitumor cytotoxicity and strong cytokine production ability, the use of $\gamma \delta T$ cells in cancer immunotherapy has received a lot of attention over the past decade.

Main text: Despite the promising potential of $\gamma \delta T$ cells, the efficacy of $\gamma \delta$ T cell immunotherapy is limited, with an average response ratio of only $21 \%$. In addition, research over the past 2 years has shown that $\gamma \delta T$ cells could also promote cancer progression by inhibiting antitumor responses, and enhancing cancer angiogenesis. As a result, $ү \delta T$ cells have a dual effect and can therefore be considered as being both "friends" and "foes" of cancer. In order to solve the sub-optimal efficiency problem of $\gamma \delta T$ cell immunotherapy, we review recent observations regarding the antitumor and protumor activities of major structural and functional subsets of human $\gamma \delta T$ cells, describing how these subsets are activated and polarized, and how these events relate to subsequent effects in cancer immunity. A mixture of both antitumor or protumor $\gamma \delta$ T cells used in adoptive immunotherapy, coupled with the fact that $\gamma \delta \mathrm{T}$ cells can be polarized from antitumor cells to protumor cells appear to be the likely reasons for the mild efficacy seen with $\gamma \delta T$ cells.

Conclusion: The future holds the promise of depleting the specific protumor $\gamma \delta T$ cell subgroup before therapy, choosing multi-immunocyte adoptive therapy, modifying the cytokine balance in the cancer microenvironment, and using a combination of $\gamma \delta T$ cells adoptive immunotherapy with immune checkpoint inhibitors.
\end{abstract}

Keywords: $\gamma \delta$ T cells, Adoptive immunotherapy, Protumor, Antitumor, Tumor microenvironment, Cytokine, Polarization

\section{Background}

$\gamma \delta \mathrm{T}$ cells are a subgroup of $\mathrm{T}$ cells with distinct $\mathrm{T}$ cell receptors (TCRs) $\gamma$ and $\delta$ chains on their surface, which account for $0.5-5 \%$ of all T-lymphocytes. This small subset of cells were first found in 1987, after the accidental discovery of third chain of the TCR ( $\gamma$ chain) in 1984 [13]. In contrast, the most $\mathrm{T}$ cells in normal human body are $\alpha \beta$ T cells $(65-70 \%)$ with TCR composed of two glycoprotein chains called $\alpha$ and $\beta$ TCR chains. These cells are generally simply referred to as "T cells". Although, $\gamma \delta \mathrm{T}$ cells are much less common than $\alpha \beta \mathrm{T}$ cells, they

*Correspondence: cuijw@jlu.edu.cn

Cancer Center, The First Hospital of Jilin University, Changchun 130021,

People's Republic of China are at their highest abundance in the gut mucosa, within a population of lymphocytes known as intraepithelial lymphocytes [3, 4]. As outstanding research on $\gamma \delta \mathrm{T}$ cells ever since, these immune cells have gained close attention than ever before. Their features include nonMHC restricted antigen recognition and an abundant cytokine secretion capacity, suggesting that they possess a high antitumor capability. These attractive features have raised expectations for their application in cancer adoptive immunotherapy [5]. Up until now, clinical trials have been conducted in numerous cancers, such as renal cell carcinoma, malignant leukemia, and advanced lung cancer, as well as others, with the majority of trials showing them to be well tolerated and safe [4-7]. 
However, in recent years, there have been a number of ongoing reports claiming that $\gamma \delta \mathrm{T}$ cells promote cancer development (i.e. have protumor activity) $[8,9]$. For example, $\gamma \delta$ T17 cells are one of the major sources of IL-17 in the cancer microenvironment [10], and IL-17 can promote cancer growth by supporting angiogenesis in gall-bladder cancer, gastric cancer, non-small cell lung carcinoma, as well as other cancers [11-14]. It has also been reported that $\gamma \delta$ T cells can increase the population of myeloid derived suppressor cells (MDSCs). MDSCs have been reported to facilitate cancer progression in several types of cancer, such as esophageal cancer, breast cancer, colorectal cancer and pre-hepatic carcinoma [15-19].

A review of clinical trials conducted in the last decade shows that $\gamma \delta \mathrm{T}$ cell-based immunotherapies are safe and well tolerated. However, the clinical benefits appeared to be mild to moderate at best and raise a number of questions. Can $\gamma \delta$ T cells inhibit cancer growth on the one hand, and promote cancer development on the other? What controls the efficiency of $\gamma \delta \mathrm{T}$ cell-based cancer immunotherapy? This review will uncover the mystery of the dual effects of $\gamma \delta \mathrm{T}$ cells in cancer immunotherapy. From "foe" to "friend," we turn our attention away from their well-known immune effector role and toward to their new-found immune suppressive regulatory role. By carefully reviewing the last decade of clinical trials and pre-clinical research, we suggest that the limited efficacy of $\gamma \delta \mathrm{T}$ cell therapies may be caused by the different effects of specific $\gamma \delta$ T cells subgroups on cancer cells, as a result of their polarization following cytokine stimulation. Based on these finding, we propose that future immunotherapeutic should focus on promoting antitumor $\gamma \delta$ T cell proliferation, while at the same time suppressing protumor $\gamma \delta \mathrm{T}$ cells. Additionally, breaking the suppressive tumor microenvironment (TME) will be another means of improving the antitumor efficiency of $\gamma \delta \mathrm{T}$ cells. In particular, the most promising strategy for future $\gamma \delta \mathrm{T}$ cell immunotherapy is proposed to be modification of the cytokine balance in the TME coupled with deletion of the specific protumor $\gamma \delta$ T cell subgroup.

\section{Classification of $\gamma \delta \mathrm{T}$ cells}

$\gamma \delta \mathrm{T}$ cells are a group of heterogeneous T cells, composed of a variety of subgroups, based on their TCRs composition and cellular function. The combinatorial variety generated by the different TCRs are thought to underlie the reason $\gamma \delta \mathrm{T}$ cells exert diverse actions in distinct pathological types of cancer (Fig. 1). As the name suggests, the $\gamma \delta$ T cell receptor contains $\delta$ and $\gamma$ chains. Based on the TCR structure, human $\gamma \delta$ T cells can be divided into four main populations based on TCR $\delta$ chain expression $(\delta 1, \delta 2, \delta 3, \delta 5)[20,21]$. Furthermore, the different TCR

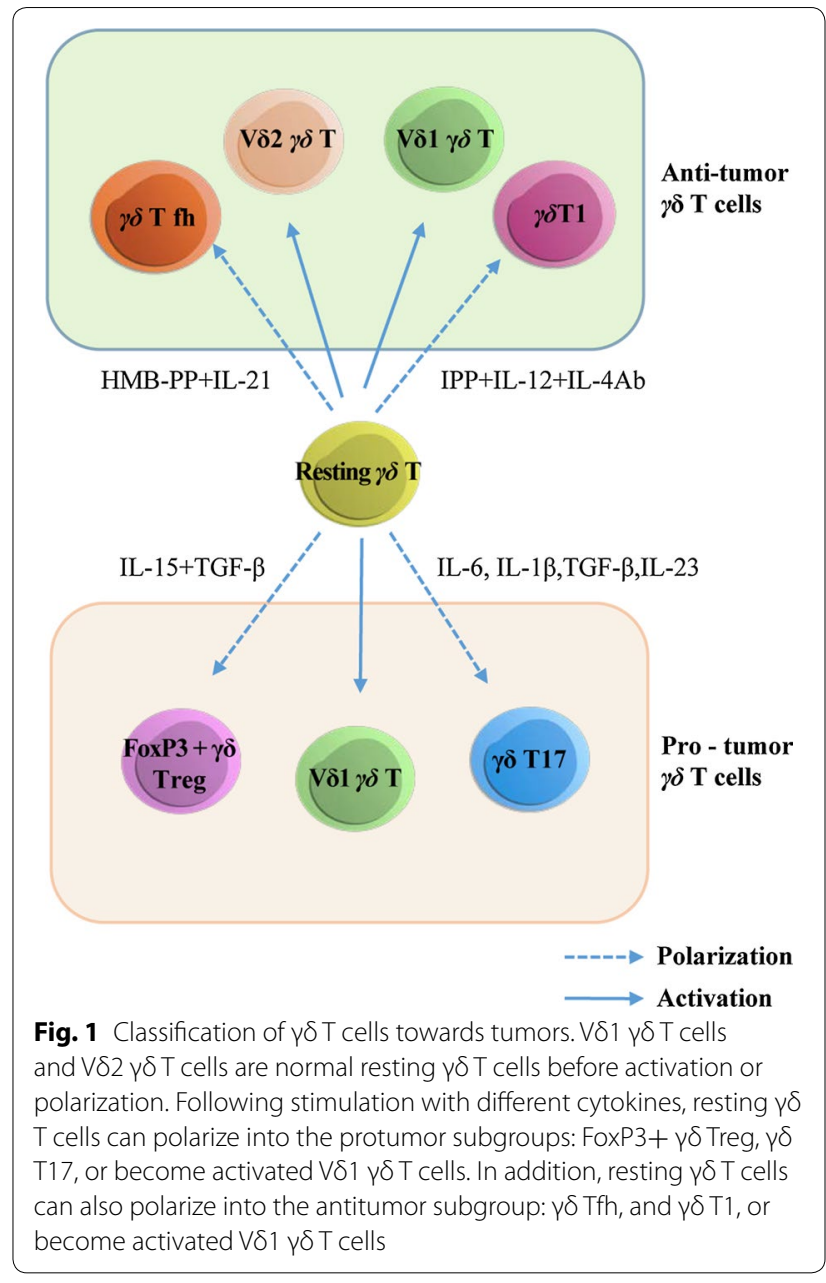

$\delta$ chains and TCR $\gamma$ chains combined together to form different $\gamma \delta$ T cell types [22, 23] (Table 1). For example, $\gamma \delta$ T cells expressing a TCR containing $\gamma$-chain variable region $9(\mathrm{~V} \gamma 9)$ and $\delta$-chain variable region $2(\mathrm{~V} \delta 2)$, are referred to as $\mathrm{V} \gamma 9 \mathrm{~V} \delta 2 \mathrm{~T}$ cells, and these cells represent the majority of $\gamma \delta \mathrm{T}$ cells in peripheral blood [24]. In both humans and mice, $\mathrm{V}_{2} 2, \mathrm{~V}_{\gamma} 3, \mathrm{~V}_{\gamma} 4, \mathrm{~V} \gamma 5, \mathrm{~V} \gamma 8, \mathrm{~V} \gamma 9$, and $V \gamma 11$ rearrangements of the $\gamma$ chain are found; in addition several $\mathrm{V}_{\gamma}$ pseudo-genes $\left(\mathrm{V}_{\gamma} 1, \mathrm{~V}_{\gamma} 5 \mathrm{P}, \mathrm{V}_{\gamma} 6, \mathrm{~V}_{\gamma} 7\right.$, and $\mathrm{V} \gamma 10)$ are present in mice but not in humans [23]. As has been shown in numerous pre-clinical and clinical studies, $\mathrm{V} \gamma 9 \mathrm{~V} \delta 2 \mathrm{~T}$ cells have potent antitumor activity. They can inhibit cancer cell proliferation, angiogenesis, lymphangiogenesis, and increase cancer cell apoptosis [25]. V $\gamma 9 \mathrm{~V} \delta 2 \mathrm{~T}$ cells can recognize phosphorylated antigens that accumulate in cancer cells, interact with the F1-ATPase expressed at the cancer cell surface, and recognize stress-induced molecules, such as the MHC class I chain-related molecules A and B (MICA and MICB), as well as UL16-binding proteins [26]. In contrast, V $\delta 1$ and $V \delta 3 \gamma \delta \mathrm{T}$ cells comprise only a minor subset of $\mathrm{T}$ 
Table 1 Structural subsets of human $\gamma \delta T$ cells

\begin{tabular}{|c|c|c|}
\hline Structure subset & Paired $V_{\gamma}$ gene & Distribution \\
\hline V $\delta 1$ & $V_{\gamma} 2, V_{\gamma} 3, V_{\gamma} 4, V_{\gamma} 5, V_{\gamma} 8, V_{\gamma} 9$ & PB, skin, gut, spleen, liver \\
\hline Vठ2 & VY9 & $\mathrm{PB}$ \\
\hline Vळ3 & $v_{\gamma 2}, v_{\gamma 3}$ & PB, liver \\
\hline V85 & $V_{y} 4$ & $\mathrm{~PB}$ \\
\hline
\end{tabular}

lymphocytes. V $\delta 1 \gamma \delta \mathrm{T}$ cells are found in normal human epithelia, dermis, spleen, and liver, as well as being found in the peripheral blood of patients with chronic viral infections and patients with leukemia [27]. $\mathrm{V} \delta 1 \gamma \delta \mathrm{T}-$ cells expanded from peripheral blood exhibit a specific cytotoxicity against B cell chronic lymphocytic leukemiaderived cells [28]. V $\delta 3 \gamma \delta \mathrm{T}$ cells are found in the liver and the gut epithelium $[29,30]$, which is rarely studied in cancer. Compared with Vy 9 V $22 \mathrm{~T}$ cells, tumor-reactive $V \delta 1 \gamma \delta \mathrm{T}$ cells do not preferentially pair with a specific $V_{\gamma}$ chain, and they can persist in circulation for a long time after stimulation [31]. Nevertheless, their role in cancer is controversial, and this subgroup will be discussed further in a later section.

Based on their function, $\gamma \delta \mathrm{T}$ cells can be divided into two subsets: effector $\gamma \delta$ T cells and regulatory $\gamma \delta$ T cells. The regulatory and effector functions of $\gamma \delta$ T cells have recently been excellently reviewed by Paul and Lal [34]. When $\gamma \delta \mathrm{T}$ cells are activated by a stimulus, these cells, which play an antitumor role by secreting cytokines, act through antibody dependent cellular cytotoxicity (ADCC) effects, as well as other processes, are referred to as effector $\gamma \delta \mathrm{T}$ cells. In contrast, $\gamma \delta \mathrm{T}$ cells, which are responsible for modulating the immune system and maintenance of immunological tolerance, are referred to as regulatory $\gamma \delta$ T cells ( $\gamma \delta$ Treg cells), and this subgroup is also named as $\gamma \delta$ suppressor T cells [32-34]. $\gamma \delta$ Treg cells promote cancer growth by impairing the function of various effector cells. $\gamma \delta$ Treg cells can induce immuno-senescence by targeting naïve $\mathrm{T}$ cells, as well as dendritic cells (DCs) [35]. $\gamma \delta$ T17 cells are another subset of pro-inflammatory regulatory $\mathrm{T}$ cells defined by their production of interleukin 17 (IL-17). In a variety of types of cancer, $\gamma \delta \mathrm{T} 17$ cells promote the accumulation and expansion of immunosuppressive cells and expedite the development of cancer [16].

\section{Plasticity of $\gamma \delta$ T cells}

Interestingly, in response to different cytokines, $\gamma \delta \mathrm{T}$ cells can shift from one phenotype to another, in a process referred to as polarization [36, 37]. This property is referred to as the plasticity of $\gamma \delta \mathrm{T}$ cells. It has been reported that $\mathrm{V} \gamma 9 \mathrm{~V} \delta 2 \mathrm{~T}$ cells can be polarized into $\gamma \delta$ T17 cells (producing only IL-17), $\gamma \delta$ T1/17 cells (producing both IFN- $\gamma$ and IL-17), $\gamma \delta$ T1 cells (producing both IFN- $\gamma$ and TNF- $\alpha$ ) and $\gamma \delta$ T2 cells (producing increased IL-4) with distinct cytokines being required for their polarization initiation and maintenance [38]. In this regard, it has been shown that IL- 6 , IL- $1 \beta$, and TGF- $\beta$ are required to generate $\gamma \delta$ T17 cells in neonates, whereas $\gamma \delta$ $\mathrm{T} 1 / 17$ cells additionally require IL-23. In adults, memory $\gamma \delta \mathrm{T} 1 / 17$ cells and $\gamma \delta \mathrm{T} 17$ cells, required IL-23, IL-1 $\beta$, and TGF- $\beta$ but not IL- 6 [39]. For $\gamma \delta$ T1 cell and $\gamma \delta$ T2 cell polarization, $\mathrm{V} \gamma 9 \mathrm{~V} \delta 2 \gamma \delta$ T cells should be stimulated with isopentenyl pyrophosphate (IPP) in the presence of Th1-priming (IL-12, anti-IL-4 Ab) or Th2-priming (IL4, anti-IL-12 Ab) conditions [40]. It has also been shown that $\mathrm{V} \gamma 9 \mathrm{~V} \delta 2 \gamma \delta \mathrm{T}$ cells can polarize toward FOXP3 $+\gamma \delta$ Treg cells following stimulation with TGF- $\beta$ and IL-15 in vitro [41]. Moreover, $\gamma \delta \mathrm{T}$ cells can polarize towards follicular B-helper T cells ( $\gamma \delta$ Tfh cells) following stimulation with IPP and IL-21, which facilitate maturing B cells to produce antibodies against foreign antigens. All in all, this broad polarization range indicates that there are no clear boundaries between the structural and functional subsets of $\gamma \delta$ cells, and it is possible to polarize $\mathrm{V} \delta 2 \mathrm{~T}$ cells into nearly all functional subsets with distinct cytokine stimulation. Cytokines, by determining $\gamma \delta$ T cell polarization, therefore ultimately define the role of $\gamma \delta \mathrm{T}$ cells in cancer.

Because of plasticity of $\gamma \delta$ T cells, these cells can therefore be viewed both as being a "friend" or a "foe" of cancer. As a "foe" of cancer, $\gamma \delta$ T cells exert both direct and indirect antitumor effects, principally due to $\mathrm{V} \gamma 9 \mathrm{~V} \delta 2 \mathrm{~T}$ cells, $\gamma \delta$ Tfh cells, $\gamma \delta$ T1 cells, as well as $V \delta 1 \gamma \delta \mathrm{T}$ cells. The term "friend of cancer," refers to a subset of $\gamma \delta \mathrm{T}$ cells, including $\gamma \delta$ T17 cells, $\gamma \delta$ Treg cells, and V $\delta 1 \gamma \delta \mathrm{T}$ cells. It should be noted that the role of $\mathrm{V} \delta 1 \gamma \delta \mathrm{T}$ cells in cancer is controversial since they have been suggested to have both an antitumor role and a protumor role [14, $42-44]$.

\section{$\gamma \delta \mathrm{T}$ cells as foes in cancer development Specific $\gamma \delta \mathrm{T}$ cells subsets play a direct antitumor role} The direct antitumor role of $\gamma \delta$ T cells has been documented from four different aspects (Fig. 2). First, after migrating to the tumor local environment, $\gamma \delta$ T cells can lyse cancer cells through the perforin-granzyme pathway [45]. For example, inhibiting the perforin-granzyme secretion capacity of $\mathrm{V} \gamma 9 \mathrm{~V} \delta 2 \mathrm{~T}$ cells reduces their ability to lyse breast cancer cell in vitro [46]. In renal cancer, $\gamma \delta \mathrm{T}$ cells display a selective lytic potential toward autologous primary renal cancer cells, but not against normal renal cells, mainly depending on the TCR and the NKG2D receptor. This lytic activity also involves the perforin-granzyme pathway [47]. In an in vitro study of head 


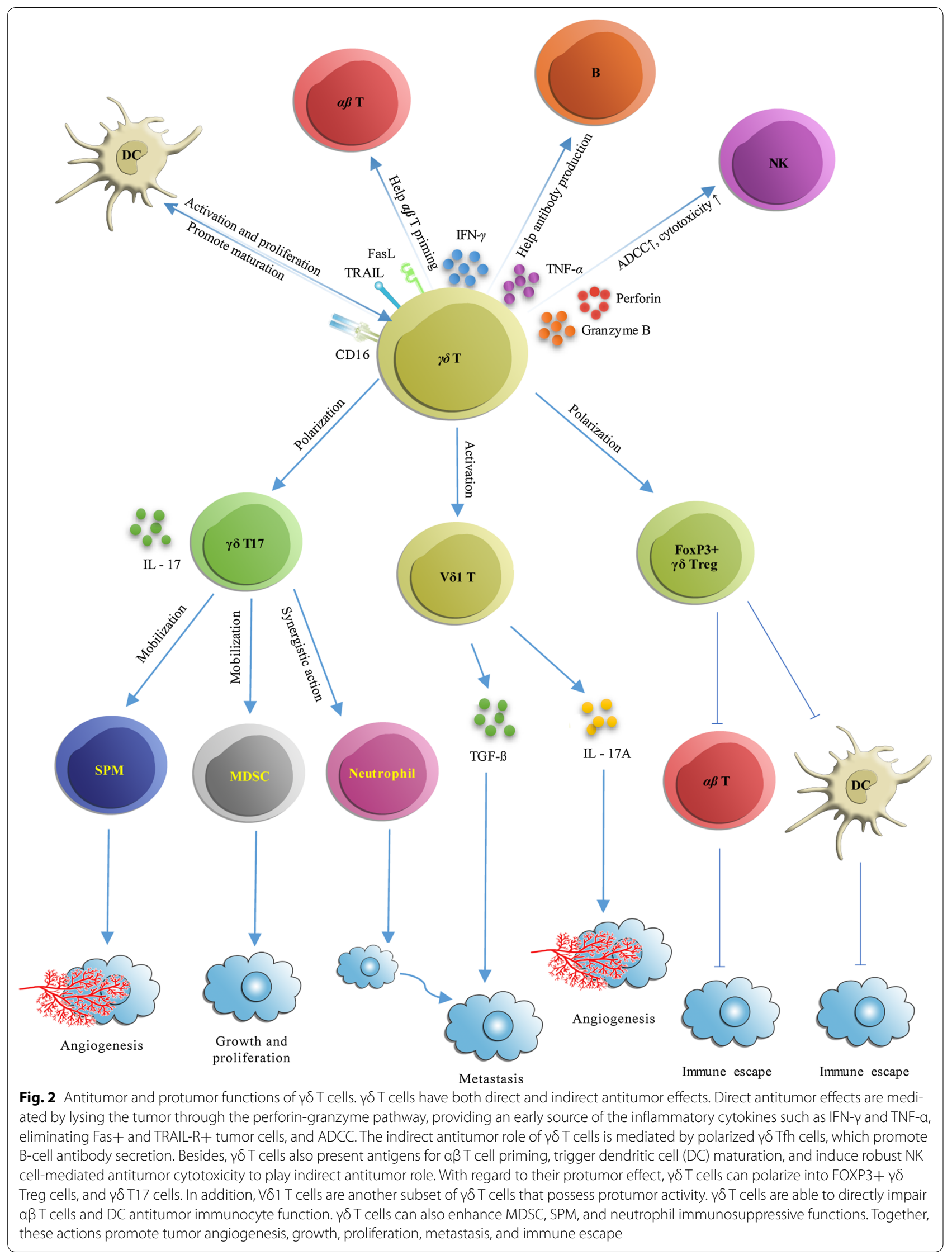


and neck squamous carcinomas, perforin-granzyme lytic activity was also derived from $\gamma \delta$ T cells [48].

Second, $\gamma \delta \mathrm{T}$ cells can eliminate cancer cells through the ligands TRAIL and FasL [49, 50]. If TRAIL is blocked, $\gamma \delta \mathrm{T}$ cell-mediated cytotoxicity activity is reduced [51]. Upregulation of Fas on osteosarcoma cells reportedly results in an enhanced susceptibility of the cells to $\gamma \delta \mathrm{T}$ cell lysis [52].

Third, $\gamma \delta$ T cells can kill cancer cells via ADCC. ADCC occurs when CD16 (FcyR III) present on $\gamma \delta$ T cells. CD16 binds to the Fc region of IgGs, which constitutes another means of $\gamma \delta \mathrm{T}$ cell target recognition, in addition to TRAIL and FasL. CD16 can also be up-regulated on $\gamma \delta$ T cells, depending on the precise biological situation. Binding to its target may trigger either cytotoxicity or other effector functions (e.g., IFN- $\gamma$ secretion) [53, 54]. The existence of the $\gamma \delta \mathrm{T}$ cell effect was also proven by Zheng et al. who cloned the extracellular domains of a $\mathrm{V} \gamma 9 \mathrm{~V} \delta 2$ TCR from ovarian cancer TILs, and conjugated them with Fc domain of human IgG1 [55]. This chimeric antibody mediated cell killing via ADCC in a dose-dependent manner. In vivo, this TCR VY9 V 22 (OT3)-Fc significantly inhibited cancer cell growth and enhanced survival in human ovarian carcinoma xenograft models.

Lastly, $\gamma \delta \mathrm{T}$ cells are important early sources of IFN $-\gamma$ and TNF- $\alpha[56,57]$. Both IFN- $\gamma$ and TNF- $\alpha$ inhibit cancer growth through several mechanisms, including the enhancement of antitumor immunity, and the inhibition of cancer angiogenesis [58]. The secretion of IFN- $\gamma$ and TNF- $\alpha$ by $\gamma \delta$ T cells is promoted by numerous stimuli, including TCR agonists, ligands of NKG2D, and certain cytokines, such as IL-12 and IL-18 [59].

Specific $\gamma \delta$ T cells subsets exert an indirect antitumor effect $\gamma \delta \mathrm{T}$ cells exert their indirect antitumor effect by interacting with B cells, DCs, $\alpha \beta$ T cells, and NK cells, respectively (Fig. 2). $\gamma \delta$ T cells have been shown to affect B cell antibody secretion in non-immunized mice. Huang et al. have shown that selective ablation of $\mathrm{V} \gamma^{4}$ and $\mathrm{V}_{\gamma} 6 \gamma \delta$ subsets of $\gamma \delta$ T cells, rather than removing all of the $\gamma \delta$ subsets, strongly affect serum Ab levels in non-immunized mice. This demonstrates that $\gamma \delta$ T cells are capable of modulating the population of pre-immune peripheral $B$ cells and their antibody productivity [60]. Caccamo et al. have observed that after co-culture of $\mathrm{V} \gamma 9 \mathrm{~V} \delta 2 \mathrm{~T}$ cells with IPP and IL-21, the $\mathrm{V} \gamma 9 \mathrm{~V} \delta 2 \mathrm{~T}$ cells polarized toward a lymphocyte subset displaying features of follicular B-helper T (Tfh) cells. These Tfh-like V $\gamma 9 \mathrm{~V} \delta 2 \mathrm{~T}$ cells could secrete IL-4, IL-10, and CXCL13, and help B cells to produce antibody in vitro. These results are in line with Bansal et al. who demonstrated that $\mathrm{V} \gamma 9 \mathrm{~V} \delta 2 \mathrm{~T}$ cells express Tfh cells markers when stimulated with IL-21 and HMB-PP, indicating that they are able to help B cells to produce antibodies, just like Tfh cells $[61,62]$.

$\gamma \delta \mathrm{T}$ cells can also act as antigen presenting cells (APCs) for $\alpha \beta \mathrm{T}$ cell priming. As far back as 2006, $\gamma \delta \mathrm{T}$ cells were first reported to have an antigen presenting function. After stimulation, the expression levels of antigen presenting molecules in $\gamma \delta$ T cells increased, including the levels of leukocyte activation receptor (CD69), the antigen presenting molecule (HLA-DR), and T cell co-stimulation and adhesion molecules (CD80, CD86, CD54, and CD40) [63]. In contrast to $\alpha \beta \mathrm{T}$ cells, $\gamma \delta \mathrm{T}$ cells, as antigen presenting cells, are able to up-regulate CD36, a scavenger receptor involved in the uptake of apoptotic cells by immature DCs and macrophages. Because of a high level of expression of CD36, $\gamma \delta$ T cells kill liver cancer cells, followed by uptake of their debris, and through their APC function induce a cancer antigenspecific CD8+ $T$ cell response [64]. Brandes et al. found that activated $\mathrm{V} \gamma 9 \mathrm{~V} \delta 2 \mathrm{~T}$ cells induce proliferation of naive $\mathrm{CD} 4+\alpha \beta \mathrm{T}$ cells, and promote their differentiation into cytotoxic T lymphocytes (CTLs) [65].

$\gamma \delta \mathrm{T}$ cells can also trigger DC maturation. In return, DCs can also induce the activation and proliferation of $\gamma \delta \mathrm{T}$ cells, enhancing their cytotoxic and immunoregulatory functions [66], which demonstrate that each of these cell types can act individually to remove cancer cells, but they can also interact synergistically [67]. Devilder et al. found that $\mathrm{V} \gamma 9 \mathrm{~V} \delta 2 \mathrm{~T}$ cells can accelerate the maturation of DCs. This DC maturation relies on a combination of cytokine TNF- $\alpha$ and cell contact dependent signals [68]. In another study, Conti et al. also point out that DC activation by $\gamma \delta$ T cells was almost all mediated through TNF- $\alpha$ and IFN- $\gamma$, and the authors further noted that this activation required CD86 and cell to cell contact (i.e. between DCs and $\gamma \delta$ T cells) [69]. In return, immature DCs, and to a lesser extent mature dendritic cells $(\mathrm{mDCs})$, are capable of enhancing the ability of $\mathrm{V} \gamma 9 \mathrm{~V} \delta 2$ $\mathrm{T}$ cells to secrete TNF- $\alpha$ [70].

Finally, $\gamma \delta$ T cells can induce robust NK cell-mediated antitumor cytotoxicity through CD137 engagement. Maniar et al. have shown that in vitro expanded $\gamma \delta \mathrm{T}$ cells can enhance NK cell cytotoxicity to NK-resistant cancers [71]. This enhanced NK cell cytolysis requires immobilized human IgG1, and co-stimulation between CD137 expressed on NK cells and CD137L expressed on $\gamma \delta$ T cells.

\section{$\gamma \delta \mathrm{T}$ cells as friends in cancer development} Specific $\gamma \delta T$ cells subsets promote cancer progression directly

$\gamma \delta \mathrm{T} 17$ cells have been reported to support cancer progression by promoting angiogenesis in gallbladder cancer, 
ovarian cancer, as well as others [11, 72]. $\gamma \delta$ T17 cells are the major source of IL-17, which plays an immunosuppressive role in cancer. In gallbladder cancer (GBC), $\gamma \delta$ T17 cells migrate toward the tumor bed through the CXCL9-CXCR3 axis. IL-17, secreted by $\gamma \delta$ T17 cells, then induces the production of vascular endothelial growth factor, as well as other angiogenesis related factors. The presence of $\gamma \delta$ T17 cells has been associated with poor survival in GBC patients [11]. After exposure to IL- 6 and TGF- $\beta$, tumor-infiltrating CCR6(-) $\gamma \delta$ T cells can be polarized toward $\gamma \delta$ T17 cells. Furthermore, IL17-deficient mice showed markedly reduced angiogenesis and consequently slower cancer progression, suggesting a significant role for $\gamma \delta \mathrm{T} 17$ cells in cancer cell growth (Fig. 2).

It has been well demonstrated that $\mathrm{V} \gamma 9 \mathrm{~V} \delta 2 \gamma \delta \mathrm{T}$ cells can polarize toward FOXP3 $+\gamma \delta$ Treg cells following stimulation with TGF- $\beta$ and IL-15 in vitro [41]. These FOXP3 $+\gamma \delta$ Treg cells have a similar function as $\alpha \beta$ Treg cells, which suppress the proliferation of anti-CD3/antiCD28 stimulated PBMCs. Additionally, V81 Treg cells have also been found to be induced in an immune suppressive TME. In breast cancer, V $\delta 1$ Treg cells, attracted by breast cancer cells, have also been shown to secrete the chemokine IP-10 [35].

$\mathrm{V} \delta 1 \gamma \delta \mathrm{T}$ cells are another subgroup of recently discovered $\gamma \delta$ T cells with protumor activity. $V \delta 1 \gamma \delta$ T cells are involved in inflammation-induced cancer progression, dependent on the production of IL-17A [73]. In another report, $\mathrm{V} \delta 1 \gamma \delta \mathrm{T}$ cells have been reported to strongly secrete TGF- $\beta$. The secreted TGF- $\beta$ can induce the epithelial to mesenchymal transition during which the cancer can escape immune detection, ultimately resulting in metastasis and cancer invasiveness [74]. With regards to $T$ helper cell suppression, peripheral human $\mathrm{V} \delta 1 \gamma \delta \mathrm{T}$ cells have a more potent regulatory potential than $\alpha \beta$ Treg cells (CD4+ CD25+ cells) [66, 75]. Therefore, $\mathrm{V} \delta 1 \gamma \delta \mathrm{T}$ cells are able to modulate the immune system, the TME, and promote cancer cell invasiveness and metastasis.

In addition, a $V \delta 1$ and $V \delta 2 \gamma \delta \mathrm{T}$ cell imbalance (i.e. an increase in the V $\delta 1: \mathrm{V} \delta 2$-ratio) has also been proven to contribute to the development of cancer [76-78]. This $\mathrm{V} \delta 1$ and $\mathrm{V} \delta 2 \gamma \delta \mathrm{T}$ cell imbalance mediated by IL-4. IL-4 inhibits the activation of naïve $V \delta 1 \gamma \delta \mathrm{T}$ cells, in a TCR-STAT6 dependent manner, and in doing so, promotes the growth of activated $\mathrm{V} \delta 1 \gamma \delta \mathrm{T}$ cells and subsequently up-regulates the number of $\mathrm{V} \delta 1 \gamma \delta$ $\mathrm{T}$ cells. These $\mathrm{V} \delta 1 \gamma \delta \mathrm{T}$ cells secrete IL-10 resulting in the inhibition of $\mathrm{V} \delta 2 \gamma \delta \mathrm{T}$ cells [79]. In the presence of IL-4, V $\delta 1 \gamma \delta \mathrm{T}$ cells secrete significantly less IFN- $\gamma$, more IL-10, and express lower NKG2D, compared with $\mathrm{V} \delta 2 \gamma \delta \mathrm{T}$ cells.

\section{$\gamma \delta \mathrm{T}$ cells impair the function of other antitumor immunocytes}

As a "friend" of cancer, $\gamma \delta$ T cells can impair the antitumor ability of immunocytes. For example, it has been reported that human breast tumor infiltrating $\mathrm{V} \delta 1 \gamma \delta \mathrm{T}$ cells could inhibit DC maturation and their APC functions, thus impairing naïve $\alpha \beta T$ cell activation and differentiation into effector $\mathrm{T}$ cells (CD4+ and CD8+ T cells) through the TLR8 signaling pathway [44]. In pancreatic ductal adenocarcinoma, it has been shown that $\gamma \delta \mathrm{T}$ cells express high levels of PD-L1 and support pancreatic oncogenesis by restraining $\alpha \beta \mathrm{T}$ cell activation [80]. It has also been discovered that tumor-derived $\gamma \delta$ Treg cells can induce cell cycle arrest of responder T cells, and that they can suppress naïve and effector $\mathrm{T}$ cells through the induction of $\mathrm{T}$ cell senescence. Further, $\gamma \delta$ Treg cells have been shown to induce DC senescence, resulting in an impairment of their phenotypic and functional features [81].

\section{$\gamma \delta \mathrm{T}$ cells enhance immunosuppressive cell function}

MDSCs have been reported to facilitate cancer progression in several types of cancers, including: breast cancer, colorectal cancer (CRC), and pre-hepatic carcinoma [15, $16,82,83]$. IL-17 is one of the main chemo-attractant driving forces for the recruitment of MDSCs [16, 82, 83]. In one CRC study, innate $\gamma \delta$ T17 cells could convert cancer-elicited inflammation into immunosuppression through MDSCs; furthermore, cancer $\gamma \delta$ T17 cells were correlated with clinicopathological features of human CRC [16]. Research has also demonstrated that $\gamma \delta$ T cells play a regulatory role in immune tolerance by mobilizing MDSC infiltration to the liver, leading to MDSC-mediated CD8 $+\mathrm{T}$ cell exhaustion [84]. $\gamma \delta \mathrm{T}$ cells secreting dermal IL-17 play a critical role in skin inflammation, and this inflammation is capable of inducing MDSCs that facilitate cancer progression by counter-acting immune surveillance and allowing for the outgrowth and proliferation of malignant cells [85, 86]. In a mouse ovarian cancer model, IL-17 secreted by CD27(-) V $\gamma 6(+) \gamma \delta$ T cells was found to immobilize small peritoneal macrophages (SPMs). These SPMs up-regulate protumor and pro-angiogenic molecular mediators, and induce ovarian cancer growth [87].

In addition, $\gamma \delta$ T cells are capable of affecting the function of neutrophils in breast cancer. Research has shown that IL- $1 \beta$ and IL- 17 secreted by $\gamma \delta$ T17 cells stimulate the expansion and polarization of neutrophils. These tumor-induced neutrophils acquire the ability to suppress cytotoxic $\mathrm{T}$ lymphocytes carrying the CD8+ antigen, which in turn facilitates the establishment of metastases [88]. In addition, these neutrophils have been found to be able to suppress peripheral $\mathrm{V} \gamma 9 \mathrm{~V} \delta 2 \mathrm{~T}$ cells $[89,90]$. In 
this way, neutrophils impair antitumor $\mathrm{V} \gamma 9 \mathrm{~V} \delta 2 \mathrm{~T}$ cells, while at the same time the synergy with $\gamma \delta$ T17 cells create an immunosuppressive TME.

Taken together, $\gamma \delta$ T cells can enhance the accumulation and function of immunosuppressive cells. These immunosuppressive cells can convert tumor-elicited inflammation into immunosuppression and promote cancer angiogenesis.

\section{Clinical application of $\gamma \delta$ T cells}

Following a review of the $\gamma \delta \mathrm{T}$ cell clinical trials conducted over the last decade, either through adoptive transfer or in vivo expansion, it is clear that $\gamma \delta \mathrm{T}$ cell therapy is safe (Table 2). $\gamma \delta \mathrm{T}$ cell based cancer immunotherapy can be divided into two categories based on either activation or expansion. The basis of the first method is to stimulate $\gamma \delta \mathrm{T}$ cells in vivo by systemic administration of phosphoantigens or nitrogen-containing bisphosphonates (N-bis). The basis of the second method is to expand $\gamma \delta$ T cells sourced from peripheral blood mononuclear cells (PBMCs) ex vivo using synthetic phosphoantigens or N-bis, followed by administration of the cultured $\gamma \delta$ T cells to the patient. $\gamma \delta$ T cells based immunotherapy have been applied to variety types of solid cancer and hematological malignancies, in which the most wide of usage is in renal cell carcinoma therapy.

Pioneering trials have defined conditions for the safe use of phosphoantigens and zoledronate for the activation of $\gamma \delta$ T cells in patients. The most common side effect flu-like symptoms without $\gamma \delta$ T cell expansion is generally induced with low doses of stimuli. Most of the adverse effects are in grade 1-2: fever, fatigue, elevation of liver transaminase, and eosinophilia [90]. Grade 3 and 4 severities of adverse events that have recurrently been reported are characterized by thrombophlebitis, thrombosis, hyperglycemia, hypocalcemia, chest and musculoskeletal pain, gastritis, myocardial infarction and renal toxicity [100].

While the safety of $\gamma \delta \mathrm{T}$ cell activation in patients has been proven, and the pharmacodynamics of phosphoantigens administered to humans has been established, the issue of limited efficacy still remains with an average response ratio of only $21 \%$ and an average clinical benefit rate of only $57 \%$. This problem could be related to activation-induced $\gamma \delta \mathrm{T}$ cell anergy, as well as to a decrease in the number of peripheral blood $\gamma \delta \mathrm{T}$ cells after infusion of the stimulants. All of these phenomena may arise as a result of properties of $\gamma \delta$ T cells [100, 101].

The $\gamma \delta \mathrm{T}$ cell anergy and the decrease in the number of peripheral blood $\gamma \delta \mathrm{T}$ cells after infusion are qualitative and quantitative problems in $\gamma \delta$ T cell therapy. With regard to the qualitative problem, the cytotoxicity of $\gamma \delta$ $\mathrm{T}$ cells may be affected by the suppressive TME as well as the cancer stage, both of which could limit the antitumor function of $\gamma \delta \mathrm{T}$ cells. In pancreatic carcinoma, $\gamma \delta$ T cell cytotoxicity ability was diminished by the levels

Table 2 Clinical trials using $\gamma \delta \mathrm{T}$ cell based cancer immunotherapies

\begin{tabular}{|c|c|c|c|c|c|c|c|c|}
\hline \multirow[t]{2}{*}{ Cell types } & \multirow[t]{2}{*}{ Diseases } & \multirow[t]{2}{*}{ Cell sources } & \multirow{2}{*}{$\begin{array}{l}\text { Number } \\
\text { of patients }\end{array}$} & \multirow{2}{*}{$\begin{array}{l}\text { Phase } \\
\text { of clinical } \\
\text { trail }\end{array}$} & \multicolumn{3}{|l|}{ Outcome } & \multirow[t]{2}{*}{ References } \\
\hline & & & & & Response (n) & RR (\%) & CBR (\%) & \\
\hline Vү9 V82T & Prostate cancer & PBMC & 18 & 1 & SD:5; PR:3; PD:3; NE:7 & 27 & 73 & Dieli et al. [50] \\
\hline$\gamma \delta \mathrm{T}$ & NSCLC & PBMC & 10 & I & SD:3; PD:5; NE:2 & 0 & 38 & Nakajima et al. [91] \\
\hline Vү9 V $82 T$ & NSCLC & PBMC & 15 & I & SD:6; PD:6; NE:3 & 0 & 50 & Sakamoto et al. [92] \\
\hline LAK:aßT, үठT, NK & Breast cancer & PBMC & 20 & 1 & PR:3; SD:1; PD:6; NE:10 & 30 & 40 & Noguchi et al. [93] \\
\hline Vy9 V82T & $\begin{array}{l}\text { Lung cancer, stom- } \\
\text { ach cancer, others }\end{array}$ & PBMC & 5 & I & $\mathrm{PD}: 2 ; \mathrm{SD}: 2 ; \mathrm{NE}: 1$ & 0 & 50 & Noguchi et al. [93] \\
\hline VY9 V82T & $\mathrm{RCC}$ & PBMC & 12 & 1 & $\mathrm{SD}: 7 ; \mathrm{PD}: 1 ; \mathrm{NE}: 4$ & 0 & 88 & Lang et al. [94] \\
\hline$\gamma \delta T$ & $\mathrm{RCC}$ & PBMC & 11 & $|/| \mid$ & CR:1; SD:5; PD:5 & 9 & 55 & Kobayashi et al. [95] \\
\hline Vү9V $82 T$ & CRC & PBMC & 6 & 1 & CR:1;PR:4; NE:1 & 100 & 100 & Izumi et al. [96] \\
\hline$\gamma \delta \top$ & NSCLC & PBMC & 15 & I & SD:6; PD:6; NE:3 & 0 & 50 & Kakimi et al. [97] \\
\hline Vү9V82T & $\mathrm{RCC}$ & In vivo expansion & 10 & 1 & PR:1; SD:6; NE:3 & 14 & 100 & Bennouna et al. [98] \\
\hline LAK:aßT, үठT, NK & $\mathrm{RCC}, \mathrm{MM}, \mathrm{AML}$ & In vivo expansion & 21 & $|/| \mid$ & CR:6; PR:2; PD:12; NE:1 & 40 & 40 & Kunzmann et al. [103] \\
\hline LAK:aßT, үઠT, NK & $\begin{array}{l}\text { Advanced hemato- } \\
\text { logical malignan- } \\
\text { cies }\end{array}$ & In vivo expansion & 4 & 1 & CR:3; PD:1 & 75 & 75 & Wilhelm et al. [99] \\
\hline Total & & & 147 & & $\begin{array}{l}\text { SD:41; CR:11; PR:13; } \\
\text { PD:47; NE:33 }\end{array}$ & 21 & 57 & \\
\hline
\end{tabular}

PBMC peripheral blood mononuclear cell, $L A K$ lymphokine activated killer cell, NSCLC non-small cell lung carcinoma, $R C C$ renal cell carcinoma, $M M$ multiple myeloma, $A M L$ acute myelocytic leukemia, $C R$ complete response, $P R$ partial response, $S D$ stable disease, $P D$ progressive disease, $N E$ not evaluable, $R R$ response rate, $\mathrm{RR}=(\mathrm{CR}+\mathrm{PR}) /$ number of evaluable patients, $C B R$ clinical benefit rate, $\mathrm{CBR}=(\mathrm{CR}+\mathrm{PR}+\mathrm{SD}) /$ number of evaluable patients, $C R C$ colorectal cancer 
of soluble MICA/B in the TME [101]. With regard to the quantitative problem, it is rational to believe that $\gamma \delta \mathrm{T}$ cell polarization may result in a decrease in the number of antitumor $\gamma \delta \mathrm{T}$ cells, where cytokines such as IL-23, IL-15, and TGF- $\beta$ largely influence cell polarization. In skin squamous cell cancer (SCC), significantly more $\gamma \delta$ T17 cells were found in SCC patients with advanced disease (stages III and IV), compared to patients with early disease (stages I and II). In contrast, the frequencies of $\mathrm{V} \delta 2 \gamma \delta \mathrm{T}$ cells were higher in SCC patients at stages I and II, but significantly decreased in patients with advanced disease (stages III and IV) [102]. This antitumor and protumor $\gamma \delta \mathrm{T}$ cell composition shift sheds light on the possibility that $\gamma \delta \mathrm{T}$ cell polarization limits their immunotherapy efficiency. Both anergy and polarization of $\gamma \delta$ $\mathrm{T}$ cells result in a reduction in their antitumor activity. Appropriate methods are therefore needed to modulate this to allow us to benefit from $\gamma \delta$ T cell immunotherapy in the long run.

To a large extent, host immune status may also affect $\gamma \delta \mathrm{T}$ cell adoptive immunotherapy, but only a few clinical trials have evaluated immune status before $\gamma \delta \mathrm{T}$ cell adoptive immunotherapy. Host immune status arises from a number of different aspects, such as composition of the TME cells, the action of immune checkpoints, cytokine levels and so on. In the context of $\gamma \delta \mathrm{T}$ cell adoptive immunotherapy, immune checkpoints such as Programmed cell death protein 1 (PD-1), potent immunosuppressive cytokines such as IL-17 and IL-4, and relevant immunocytes such as neutrophils are all involved in $\gamma \delta \mathrm{T}$ cell cytotoxic immune responses. Therefore, an evaluation of the patient's immune status before commencing $\gamma \delta$ T cell immunotherapy will minimize the likelihood of treatment failure and provide the patient with the most appropriate treatment options.

To broaden the application of $\gamma \delta \mathrm{T}$ cell-based adaptive immunotherapy, there are still many limitations that need to be resolved, such as how to switch the suppressive TME into a normal environment, and how to attract more $\gamma \delta$ T cells capable of targeting cancer cells.

\section{Prospects for $\gamma \delta \mathrm{T}$ cell-based immunotherapies}

$\gamma \delta \mathrm{T}$ cell-based immunotherapies are imperfect, which likely arises from the fact that only certain of the $\gamma \delta \mathrm{T}$ cells have robust antitumor effects, whereas others have a potent protumor function. These aspects will be discussed below from the viewpoint of the cytokine effects and the suppressive TME (Fig. 3) [103].

As either "foe" or "friend" of cancer, $\gamma \delta$ T cells are double-faced immunocytes that play a role in cancer progression. As discussed above, $\gamma \delta \mathrm{T}$ cells are a group of heterogeneous $\mathrm{T}$ cells, the combinatorial variety generated by the different TCRs are thought to explain why $\gamma \delta$ $\mathrm{T}$ cells exert diverse actions in distinct TME, such as $\mathrm{V} \delta 1$ $\gamma \delta \mathrm{T}$ cells, have a controversial role in cancer immunity. It is logical to conduct $\gamma \delta \mathrm{T}$ cell functional identification and elimination protumor subgroup before the $\gamma \delta$ T cells are transferred into the patient. Furthermore, in vivo expansion creates a possibility for protumor subset proliferation to occur. This indicates that in vivo expansion

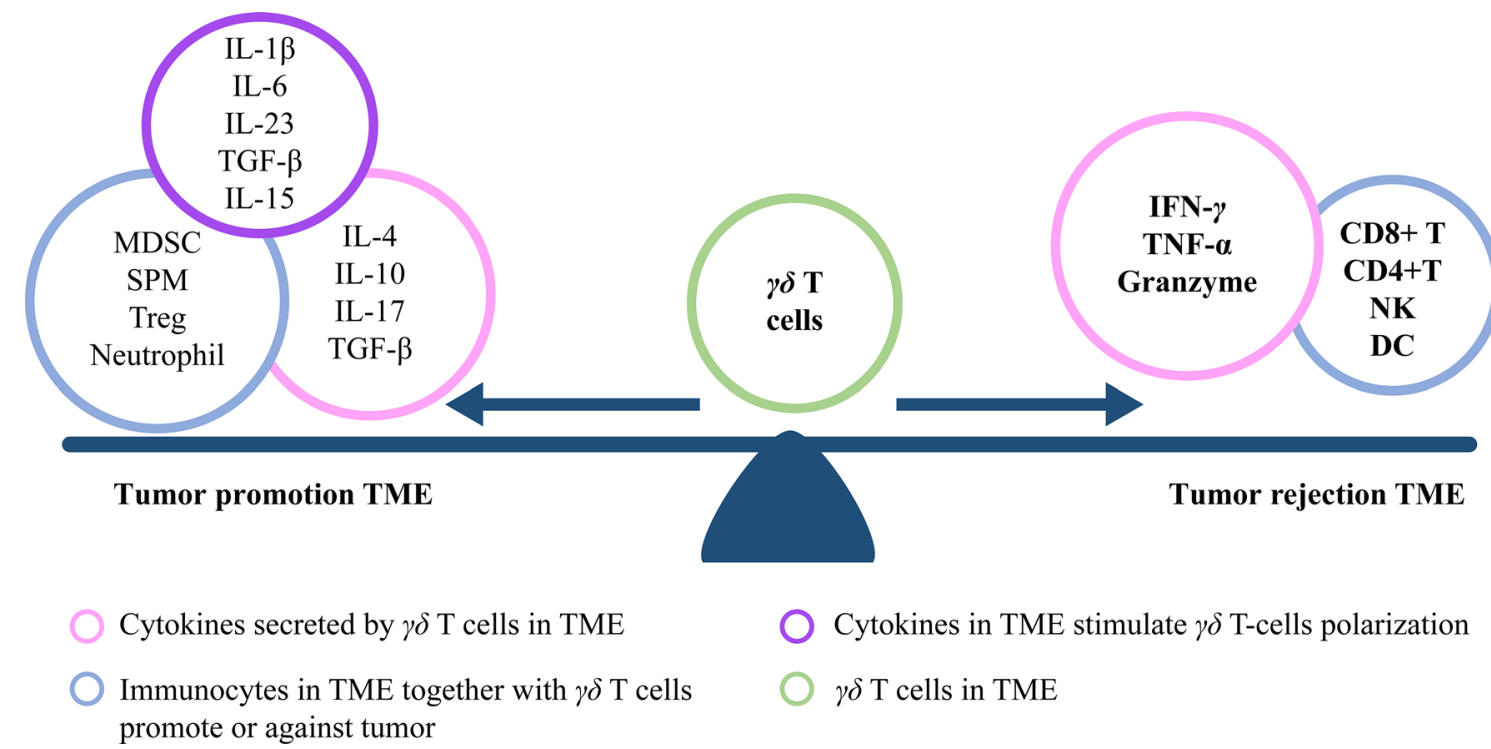

Fig. 3 The functions of $\gamma \delta T$ cells are influenced by the TME. The balance of pro- and anti-inflammatory cytokines and the cellular state govern the function of $\gamma \delta T$ cells. Tumor and stromal cells produce a variety of cytokines and chemokines that either contribute to or disrupt the development of a pro-tumorigenic niche. These factors can also reprogram $\gamma \delta T$ cells to adopt a protumor or antitumor state 
should avoid an immunosuppressive TME, which increases the possibility of $\gamma \delta$ T cells protumor polarization. To solve this problem, we suggest that $\gamma \delta$ T cellbased immunotherapies should be conducted at an early TNM stage to avoid an immunosuppressive TME, and that combination of $\gamma \delta \mathrm{T}$ cell-based immunotherapies with chemotherapy or multi-immunocyte immunotherapy could also be used against the stubborn immunosuppressive TME. Combination of $\gamma \delta$ T cells with other cytotoxic $\mathrm{T}$ cells [e.g., $\alpha \beta \mathrm{T}$ cells or cytokine-induced killer (CIK) cells] might also enhance therapeutic efficacy, owing to a two-pronged synergism: non-MHC restricted $\gamma \delta \mathrm{T}$ cells and tumor-specific adaptive response $\mathrm{T}$ cells. In so doing, multi-immunocyte adoptive immunotherapy will widen the scope of immune responsiveness to include cancer cells, and even cancer stem cells [104, 105].

Moreover, $\gamma \delta$ T cells are capable of changing their function in response to cytokine stimulation. Depending on the stimulation by different cytokines in TME, they can change their function toward being either antitumor or protumor. Therefore, cytokine balance is a very important factor in the tumor immune microenvironment. Artificial modification of the TME cytokine balance could be another promising way to amplify the effect of $\gamma \delta$ T cells. In this regard, the important cytokines include IL-23, IL-1 $\beta$, IL-15, IL-17, IL-4, IL-10, IL-36y, and TGF- $\beta$. We advocate that levels of IL-17 should be routinely measured to predict the immune status before $\gamma \delta \mathrm{T}$ cell adoptive immunotherapy is initiated. There are also some cytokines in the TME that enhance the antitumor function of $\gamma \delta \mathrm{T}$ cells and inhibit the protumor $\gamma \delta \mathrm{T}$ cells responses. As IL-21 has been proven capable of inhibiting $\gamma \delta \mathrm{T} 17$ cell protumor cell responses, further research on IL-21 should be conducted in human cancer [106]. It has been shown that IL-36 $\gamma$ acts synergistically with TCR signaling and/or that IL-12 can stimulate $\gamma \delta$ T cells. IL-36 $\gamma$ is able to promote IFN- $\gamma$ production by CD8 $+\mathrm{T}$ cells, NK cells, and $\gamma \delta \mathrm{T}$ cells. IL-36 $\gamma$ transforms the TME in favor of cancer eradication and exerts strong antitumor effects [107]. IL-18 has also been found to have the ability to promote the expansion of $\gamma \delta$ T cells with potent antitumor activity, such as those that produce GM-CSF, IFN- $\gamma$, and TNF- $\alpha$ at high levels $[108,109]$. Furthermore, the addition of IL-15 to $\gamma \delta$ T cell cultures also results in a more activated phenotype, a higher proliferative capacity, a more pronounced $\mathrm{T}$ helper 1 polarization, and an increased cytotoxic capacity of $\gamma \delta$ T cells [110]. All of these data support the rationale of exploring the use of cytokines in clinical adoptive therapy protocols that employ $\gamma \delta \mathrm{T}$ cells.

Combination of $\gamma \delta \mathrm{T}$ cells adoptive immunotherapy with immune check point inhibitors is another approach that could be used to enhance the antitumor activity of immune effector of these cells. As the above research has shown, the interaction between PD- 1 on $\alpha \beta$ T cells and its ligand PD-L1 on $\gamma \delta$ T cells restrains $\alpha \beta$ T cell activation. Logically, therefore another tactic is to block the immune checkpoint interaction in order to enhance the cytotoxic activity of antitumor cells. In this regard, and beyond PD-1, there are many immune checkpoint inhibitors that target molecules such as CTLA-4, IDO, VISTA, Galectin-9, LAG-3, and TIM-3. Moreover, ten cell surface proteins have been identified that were statistically differentially expressed between " $\gamma \delta$-susceptible" and " $\gamma \delta$-resistant" hematopoietic malignancy. Three of these genes (ULBP1, TFR2, and IFITM1) are associated with increased susceptibility to $\mathrm{V} \gamma 9 \mathrm{~V} \delta 2 \mathrm{~T}$ cell cytotoxicity, whereas the other seven (CLEC2D, NRP2, SELL, PKD2, KCNK12, ITGA6 and SLAMF1) are enriched in resistant cancers. These immune checkpoints therefore provide a wide range of different ways to improve $\gamma \delta$ T cell adoptive immunotherapy [102-116].

\section{Conclusions}

The limited efficiency of $\gamma \delta$ T cell based cancer immunotherapy may be because of their dual nature. Their actions as either "friends" or "foe" of cancer is heavily influenced by the cytokines present in the TME. A mixture of both anti- or pro-tumor $\gamma \delta$ T cells used in adoptive immunotherapy, coupled with the fact that $\gamma \delta \mathrm{T}$ cells can be polarized from antitumor cells to protumor cells are likely reasons for the low efficacy seen with $\gamma \delta$ $\mathrm{T}$ cells. This review is the first to analyze the dual effect mechanism of $\gamma \delta$ T cells and we further propose a means to improve the effect of $\gamma \delta \mathrm{T}$ cells. The future holds the promise of depleting the specific protumor $\gamma \delta$ T cell subgroup before therapy, multi-immunocyte adoptive therapy, modification of the cytokine balance in the TME, and the combination of $\gamma \delta \mathrm{T}$ cells adoptive immunotherapy with immune checkpoint inhibitors. Only if we properly handle these cells, can we benefit from $\gamma \delta$ T cell immunotherapy in the long run.

\footnotetext{
Abbreviations

AML: acute myelocytic leukemia; ADCC: antibody-dependent cellular cytotoxicity; APC: antigen presenting cells; CAR: chimeric antigen receptor; CR: complete response; CRC: colorectal cancer; CBR: clinical benefit rate; CTLs: cytotoxic T lymphocytes; CTLA-4: cytotoxic T lymphocyte-associated protein-4; DCs: dendritic cells; GBC: gallbladder cancer; IL-17: interleukin-17; LAK: lymphokine activated killer cells; mDCs: myeloid dendritic cells; MSC: mesenchymal stem cell; MDSC: myeloid derived suppressor cells; MM: multiple myeloma; MICA: MHC class I chain-related molecule A; MICB: MHC class I chain-related molecule B; NE: not evaluable; NSCLC: non-small cell lung carcinoma; PBMC: peripheral blood mononuclear cells; RCC: renal cell carcinoma; RR: response rate; PD: progressive disease; PD-1: programmed death-1; PR: partial response; SCC: squamous cell cancer; SD: stable disease; SPMs: small peritoneal macrophages; TCR: T cell receptor; Tfh: follicular B-helper T; TME: tumor microenvironment; TRAIL: tumor necrosis factor-related apoptosisinducing ligand.
} 


\section{Authors' contributions}

JWC conceived this review. YJZ scrutinized the relevant research and wrote thereview. CN and JWC reviewed and edited the manuscript. All authors have contributed to revising the manuscripts. All authors read and approved the final manuscript.

\section{Acknowledgements}

Not applicable.

\section{Competing interests}

The authors declare that they have no competing interests.

\section{Availability of data and materials}

Data sharing not applicable to this article as no datasets were generated or analyzed during the current study.

\section{Consent for publication}

Not applicable.

\section{Ethics approval and consent to participate}

Not applicable.

\section{Funding}

This work was supported by grants from National Natural Science Foundation of China (Grant 816722751004388), the National Key research and Development Program of China (Grant 2016YFC1303800), the Key Laboratory Construction Project of Science and Technology Department (Grant $20170622011 \mathrm{JC}$ ), the Industrial Research and Development Project of Development and Reform Commission of Jilin Province (Grant 2017C022), and the Project of Development and Reform Commission of Jilin Province (Grant 2014N147) to JWC.

\section{Publisher's Note}

Springer Nature remains neutral with regard to jurisdictional claims in published maps and institutional affiliations.

Received: 2 September 2017 Accepted: 30 December 2017 Published online: 10 January 2018

\section{References}

1. Born W, Miles C, White J, O'Brien R, Freed JH, Marrack P, Kappler J, Kubo RT. Peptide sequences of T-cell receptor delta and gamma chains are identical to predicted $X$ and gamma proteins. Nature. 1987;330:572-4.

2. Hayday AC, Saito H, Gillies SD, Kranz DM, Tanigawa G, Eisen HN, Tonegawa S. Structure, organization, and somatic rearrangement of $\mathrm{T}$ cell gamma genes. Cell. 1985;40:259-69.

3. Holtmeier W, Kabelitz D. $\gamma \delta$ T cells link innate and adaptive immune responses. In: Kabelitz D, Schröder JM, editors. Mechanisms of epithelial defense, vol. 86. Basel: Karger Publishers; 2005. p. 151-83.

4. Vantourout $\mathrm{P}$, Hayday A. Six-of-the-best: unique contributions of gammadelta T cells to immunology. Nat Rev Immunol. 2013;13:88-100.

5. Dar AA, Patil RS, Chiplunkar SV. Insights into the relationship between toll like receptors and gamma delta t cell responses. Front Immunol. 2014;5:366.

6. Bonneville M, Chen ZW, Dechanet-Merville J, Eberl M, Fournie JJ, Jameson JM, et al. Chicago 2014-30 years of gammadelta T cells. Cell Immunol. 2015;296:3-9.

7. Yamasaki A, Onishi H, Morisaki T, Katano M. Induction of cytotoxic T lymphocytes by CEA peptide-pulsed gammadelta T cells isolated from patients with advanced cancer. Anticancer Res. 2011;31:2419-24.

8. Rei M, Pennington DJ, Silva-Santos B. The emerging protumor role of gammadelta T lymphocytes: implications for cancer immunotherapy. Cancer Res. 2015;75:798-802.

9. Silva-Santos B, Serre K, Norell H. Gammadelta T cells in cancer. Nat Rev Immunol. 2015;15:683-91.

10. Silva-Santos B. Promoting angiogenesis within the tumor microenvironment: the secret life of murine lymphoid IL-17-producing gammadelta T cells. Eur J Immunol. 2010:40:1873-6.
11. Patil RS, Shah SU, Shrikhande SV, Goel M, Dikshit RP, Chiplunkar SV. IL17 producing gammadelta $T$ cells induce angiogenesis and are associated with poor survival in gallbladder cancer patients. Int J Cancer. 2016;139:869-81.

12. Wu X, Yang T, Liu X, Guo JN, Xie T, Ding Y, et al. IL-17 promotes tumor angiogenesis through Stat3 pathway mediated upregulation of VEGF in gastric cancer. Tumor Biol. 2016;37:5493-501.

13. Pan B, Shen J, Cao J, Zhou Y, Shang L, Jin S, et al. Interleukin-17 promotes angiogenesis by stimulating VEGF production of cancer cells via the STAT3/GIV signaling pathway in non-small-cell lung cancer. Sci Rep. 2015:5:16053.

14. Yan J, Huang J. Innate $\gamma \delta T 17$ cells convert cancer-elicited inflammation into immunosuppression through myeloid-derived suppressor cells. Oncoimmunology. 2014;3:e953423.

15. Kong $X$, Sun $R$, Chen $Y$, Wei $H$, Tian Z. $\gamma \delta T$ cells drive myeloid-derived suppressor cell-mediated CD8+ T cell exhaustion in hepatitis B virus_induced immunotolerance. J Immunol. 2014;193:1645-53.

16. Wu P, Wu D, Ni C, Ye J, Chen W, Hu G, et al. GammadeltaT17 cells promote the accumulation and expansion of myeloid-derived suppressor cells in human colorectal cancer. Immunity. 2014:40:785-800.

17. Qu P, Wang LZ, Lin PC. Expansion and functions of myeloid-derived suppressor cells in the tumor microenvironment. Cancer Lett. 2016:380:253-6.

18. Karakasheva TA, Waldron TJ, Eruslanov E, Kim SB, Lee JS, O'Brien S, Hicks PD, Basu D, Singhal S, Malavasi F, Rustgi AK. CD38-Expressing myeloidderived suppressor cells promote tumor growth in a murine model of esophageal cancer. Cancer Res. 2015;75:4074-85.

19. Chafe SC, Lou Y, Sceneay J, Vallejo M, Hamilton MJ, McDonald PC, Bennewith KL, Moller A, Dedhar S. Carbonic anhydrase IX promotes myeloid-derived suppressor cell mobilization and establishment of a metastatic niche by stimulating G-CSF production. Cancer Res. 2015;75:996-1008.

20. Kabelitz D, Marischen L, Oberg H-H, Holtmeier W, Wesch D. Epithelial defence by $\gamma \delta$ T cells. Int Arch Allergy Immunol. 2005;137:73-81.

21. Willcox CR, Pitard V, Netzer S, Couzi L, Salim M, Silberzahn T, Moreau JF, Hayday AC, Willcox BE, Dechanet-Merville J. Cytomegalovirus and tumor stress surveillance by binding of a human gammadelta $T$ cell antigen receptor to endothelial protein $C$ receptor. Nat Immunol. 2012;13:872-9.

22. Wu D, Wu P, Qiu F, Wei Q, Huang J. Human gammadeltaT-cell subsets and their involvement in tumor immunity. Cell Mol Immunol. 2017:14:245-53.

23. Adams EJ, Gu S, Luoma AM. Human gamma delta T cells: evolution and ligand recognition. Cell Immunol. 2015;296:31-40.

24. Dimova T, Brouwer M, Gosselin F, Tassignon J, Leo O, Donner C, et al. Effector Vgamma9Vdelta2 T cells dominate the human fetal gammadelta T-cell repertoire. Proc Natl Acad Sci USA. 2015;112:E556-65.

25. Di Carlo E, Bocca P, Emionite L, Cilli M, Cipollone G, Morandi F, et al. Mechanisms of the antitumor activity of human Vgamma9Vdelta2 $T$ cells in combination with zoledronic acid in a preclinical model of neuroblastoma. Mol Ther. 2013;21:1034-43.

26. Braza MS, Klein B. Anti-tumour immunotherapy with Vgamma9Vdelta2 T lymphocytes: from the bench to the bedside. Br J Haematol. 2013;160:123-32.

27. Almeida AR, Correia DV, Fernandes-Platzgummer A, da Silva CL, da Silva MG, Anjos DR, et al. Delta one T cells for immunotherapy of chronic lymphocytic leukemia: clinical-grade expansion/differentiation and preclinical proof of concept. Clin Cancer Res. 2016;22:5795-804

28. Siegers GM, Dhamko H, Wang XH, Mathieson AM, Kosaka Y, Felizardo TC, et al. Human Vdelta1 gammadelta T cells expanded from peripheral blood exhibit specific cytotoxicity against B-cell chronic lymphocytic leukemia-derived cells. Cytotherapy. 2011;13:753-64.

29. Mangan BA, Dunne MR, O'Reilly VP, Dunne PJ, Exley MA, O'Shea D, et al. Cutting edge: CD1d restriction and Th1/Th2/Th17 cytokine secretion by human Vdelta3 T cells. J Immunol. 2013;191:30-4.

30. Ramirez K, Witherden DA, Havran WL. All hands on DE (T) C: epithelial-resident $\gamma \delta T$ cells respond to tissue injury. Cell Immunol. 2015:296:57-61.

31. Siegers GM, Lamb LS Jr. Cytotoxic and regulatory properties of circulating Vdelta1+ gammadelta T cells: a new player on the cell therapy field? Mol Ther. 2014;22:1416-22. 
32. Hall JE. Guyton and Hall textbook of medical physiology. Philadelphia: Elsevier Health Sciences; 2015

33. Wesch D, Peters $C$, Siegers GM. Human gamma delta T regulatory cells in cancer: fact or fiction? Front Immunol. 2014;5:598.

34. Paul S, Lal G. Regulatory and effector functions of gamma-delta $(\gamma \delta)$ $T$ cells and their therapeutic potential in adoptive cellular therapy for cancer. In J Cancer. 2016;139:976-85.

35. Ye J, Ma C, Wang F, Hsueh EC, Toth K, Huang Y, et al. Specific recruitment of gammadelta regulatory $T$ cells in human breast cancer. Cancer Res. 2013;73:6137-48.

36. Lafont V, Sanchez F, Laprevotte E, Michaud H-A, Gros L, Eliaou J-F, et al. Plasticity of $\gamma \delta T$ cells: impact on the anti-tumor response. Front Immunol. 2014;5:622.

37. Presti LE, Dieli F, Meraviglia S. Tumor-infiltrating gammadelta T lymphocytes: pathogenic role, clinical significance, and differential programing in the tumor microenvironment. Front Immunol. 2014;5:607.

38. Caccamo N, La Mendola C, Orlando V, Meraviglia S, Todaro M, Stassi G, et al. Differentiation, phenotype, and function of interleukin-17-producing human VgammagVdelta2 T cells. Blood. 2011;118:129-38.

39. Ness-Schwickerath KJ, Jin C, Morita CT. Cytokine requirements for the differentiation and expansion of IL-17A- and IL-22-producing human Vgamma2 Vdelta2 T cells. J Immunol. 2010;184:7268-80

40. Wesch D, Glatzel A, Kabelitz D. Differentiation of resting human peripheral blood $\gamma \delta$ T cells toward Th1- or Th2-phenotype. Cell Immunol. 2001;212:110-7.

41. Casetti R, Agrati C, Wallace M, Sacchi A, Martini F, Martino A, et al. Cutting edge: TGF-beta1 and IL-15 Induce FOXP3+ gammadelta regulatory T cells in the presence of antigen stimulation. J Immunol. 2009;183:3574-7.

42. Correia DV, Fogli M, Hudspeth K, da Silva MG, Mavilio D, Silva-Santos B. Differentiation of human peripheral blood Vdelta1+T cells expressing the natural cytotoxicity receptor NKp30 for recognition of lymphoid leukemia cells. Blood. 2011;118:992-1001.

43. Devaud C, Rousseau B, Netzer S, Pitard V, Paroissin C, Khairallah C, et al. Anti-metastatic potential of human Vdelta1 (+) gammadelta T cells in an orthotopic mouse xenograft model of colon carcinoma. Cancer Immunol Immunother. 2013;62:1199-210.

44. Peng G, Wang HY, Peng W, Kiniwa Y, Seo KH, Wang RF. Tumor-infiltrating gammadelta $T$ cells suppress $T$ and dendritic cell function via mechanisms controlled by a unique toll-like receptor signaling pathway. Immunity. 2007;27:334-48.

45. Niu C, Jin H, Li M, Xu J, Xu D, Hu J, et al. In vitro analysis of the proliferative capacity and cytotoxic effects of ex vivo induced natural killer cells, cytokine-induced killer cells, and gamma-delta T cells. BMC Immunol. 2015;16:61.

46. Dhar S, Chiplunkar SV. Lysis of aminobisphosphonate-sensitized MCF-7 breast tumor cells by Vgamma9 Vdelta2 T cells. Cancer Immun. 2010;10:10.

47. Viey E, Fromont G, Escudier B, Morel Y, Da Rocha S, Chouaib S, et al. Phosphostim-activated $\gamma \delta \mathrm{T}$ cells kill autologous metastatic renal cell carcinoma. J Immunol. 2005;174:1338-47.

48. Alexander AA, Maniar A, Cummings J-S, Hebbeler AM, Schulze DH, Gastman BR, et al. Isopentenyl pyrophosphate-activated CD56+ $\gamma \delta$ T lymphocytes display potent antitumor activity toward human squamous cell carcinoma. Clin Cancer Res. 2008;14:4232-40.

49. Todaro M, D'Asaro M, Caccamo N, lovino F, Francipane MG, Meraviglia S, et al. Efficient killing of human colon cancer stem cells by $\gamma \delta \mathrm{T}$ lymphocytes. J Immunol. 2009;182:7287-96.

50. Dieli F, Vermijlen D, Fulfaro F, Caccamo N, Meraviglia S, Cicero G, et al. Targeting human $\gamma \delta \mathrm{T}$ cells with zoledronate and interleukin-2 for immunotherapy of hormone-refractory prostate cancer. Cancer Res. 2007:67:7450-7.

51. Dokouhaki P, Schuh NW, Joe B, Allen CA, Der SD, Tsao MS, et al. NKG2D regulates production of soluble TRAlL by ex vivo expanded human gammadelta T cells. Eur J Immunol. 2013;43:3175-82.

52. Li Z, Xu Q, Peng H, Cheng R, Sun Z, Ye Z. IFN- $y$ enhances HOS and U2OS cell lines susceptibility to $\gamma \delta T$ cell-mediated killing through the Fas/Fas ligand pathway. Int Immunopharmacol. 2011;11:496-503.

53. Fisher JP, Yan M, Heuijerjans J, Carter L, Abolhassani A, Frosch J, et al. Neuroblastoma killing properties of Vdelta2 and Vdelta2-negative
gammadeltaT cells following expansion by artificial antigen-presenting cells. Clin Cancer Res. 2014;20:5720-32.

54. Couzi L, Pitard V, Sicard X, Garrigue I, Hawchar O, Merville P, et al. Antibody-dependent anti-cytomegalovirus activity of human gammadelta T cells expressing CD16 (FcgammaRIlla). Blood. 2012;119:1418-27.

55. Zheng J, Guo Y, Ji X, Cui L, He W. A novel antibody-like TCRgammadeltaIg fusion protein exhibits antitumor activity against human ovarian carcinoma. Cancer Lett. 2013;34:1150-8.

56. Gao Y, Yang W, Pan M, Scully E, Girardi M, Augenlicht LH, et al. $\gamma \delta T$ cells provide an early source of interferon $\gamma$ in tumor immunity. J Exp Med. 2003;198:433-42.

57. Ramstead AG, Jutila MA. Complex role of gammadelta T-cell-derived cytokines and growth factors in cancer. J Interferon Cytokine Res. 2012;32:563-9.

58. Li H, Luo K, Pauza CD. TNF-a is a positive regulatory factor for human Vy2V82 T cells. J Immunol. 2008;181:7131-7.

59. Sedlak C, Patzl M, Saalmuller A, Gerner W. IL-12 and IL-18 induce interferon-gamma production and de novo $\mathrm{CD} 2$ expression in porcine gammadelta T cells. Dev Comp Immunol. 2014;47:115-22.

60. Huang Y, Getahun A, Heiser RA, Detanico TO, Aviszus K, Kirchenbaum GA, et al. Gammadelta T cells shape preimmune peripheral B cell populations. J Immunol. 2016;196:217-31.

61. Caccamo N, Todaro M, La Manna MP, Sireci G, Stassi G, Dieli F. IL-21 regulates the differentiation of a human gammadelta $T$ cell subset equipped with B cell helper activity. PLoS ONE. 2012;7:e41940.

62. Bansal RR, Mackay CR, Moser B, Eberl M. IL-21 enhances the potential of human gammadelta T cells to provide B-cell help. Eur J Immunol. 2012;42:110-9.

63. Brandes M, Willimann K, Moser B. Professional antigen-presentation function by human gammadelta T Cells. Science. 2005;309:264-8.

64. Muto M, Baghdadi M, Maekawa R, Wada H, Seino K. Myeloid molecular characteristics of human gammadelta $T$ cells support their acquisition of tumor antigen-presenting capacity. Cancer Immunol Immunother. 2015;64:941-9.

65. Mao C, Mou X, Zhou Y, Yuan G, Xu C, Liu H, et al. Tumor-activated $T C R y \delta+T$ cells from gastric cancer patients induce the antitumor immune rResponse of TCRa $\beta+T$ cells via their antigen-presenting celllike effects. J Immunol Res. 2014;2014:593562.

66. Van Acker HH, Anguille S, Van Tendeloo VF, Lion E. Empowering gamma delta T cells with antitumor immunity by dendritic cell-based immunotherapy. Oncoimmunology. 2015;4:e1021538.

67. Moser B, Eberl M. Gammadelta T-APCs: a novel tool for immunotherapy? Cell Mol Life Sci. 2011;68:2443-52.

68. Munz C, Steinman RM, Fujii S. Dendritic cell maturation by innate lymphocytes: coordinated stimulation of innate and adaptive immunity. J Exp Med. 2005;202:203-7.

69. Conti L, Casetti R, Cardone M, Varano B, Martino A, Belardelli F, et al. Reciprocal activating interaction between dendritic cells and pamidronate-stimulated $\gamma \delta$ T cells: role of CD86 and inflammatory cytokines. J Immunol. 2005;174:252-60.

70. Devilder MC, Maillet S, Bouyge-Moreau I, Donnadieu E, Bonneville M, Scotet E. Potentiation of antigen-stimulated $\mathrm{V}$ gamma $9 \mathrm{~V}$ delta $2 \mathrm{~T}$ cell cytokine production by immature dendritic cells (DC) and reciprocal effect on DC maturation. J Immunol. 2006;176:1386-93.

71. Maniar A, Zhang X, Lin W, Gastman BR, Pauza CD, Strome SE, et al. Human $\gamma \delta$ T lymphocytes induce robust NK cell—mediated antitumor cytotoxicity through CD137 engagement. Blood. 2010;116:1726-33.

72. Wakita D, Sumida K, Iwakura Y, Nishikawa H, Ohkuri T, Chamoto K, et al. Tumor-infiltrating IL-17-producing gammadelta T cells support the progression of tumor by promoting angiogenesis. Eur J Immunol. 2010:40:1927-37.

73. Kimura Y, Nagai N, Tsunekawa N, Sato-Matsushita M, Yoshimoto T, Cua DJ, et al. IL-17A-producing CD30(+) Vdelta1 T cells drive inflammationinduced cancer progression. Cancer Sci. 2016;107:1206-14.

74. Yang J, Weinberg RA. Epithelial-mesenchymal transition: at the crossroads of development and tumor metastasis. Dev Cell. 2008;14:818-29.

75. Kuhl AA, Pawlowski NN, Grollich K, Blessenohl M, Westermann J, Zeitz $\mathrm{M}$, et al. Human peripheral gammadelta T cells possess regulatory potential. Immunology. 2009;128:580-8. 
76. Rong L, Li K, Li R, Liu HM, Sun R, Liu XY. Analysis of tumor-infiltrating gamma delta T cells in rectal cancer. World J Gastroenterol. 2016:22:3573-80.

77. Wistuba-Hamprecht K, Di Benedetto S, Schilling B, Sucker A, Schadendorf D, Garbe C, et al. Phenotypic characterization and prognostic impact of circulating gammadelta and alphabeta T cells in metastatic malignant melanoma. Int J Cancer. 2016;138:698-704.

78. Wistuba-Hamprecht K, Martens A, Haehnel K, Foppen MG, Yuan J, Postow MA, et al. Proportions of blood-borne V $\delta 1+$ and $V \delta 2+T$ cells are associated with overall survival of melanoma patients treated with ipilimumab. Eur J Cancer. 2016:64:116-26.

79. Mao Y, Yin S, Zhang J, Hu Y, Huang B, Cui L, et al. A new effect of IL-4 on human gammadelta $T$ cells: promoting regulatory $V$ delta $1 \mathrm{~T}$ cells via IL-10 production and inhibiting function of Vdelta2 T cells. Cell Mol Immunol. 2016;13:217-28.

80. Daley D, Zambirinis CP, Seifert L, Akkad N, Mohan N, Werba G, et al. Gammadelta $T$ cells support pancreatic oncogenesis by restraining alphabeta T cell activation. Cell. 2016;66:1485-99.

81. Ye J, Ma C, Hsueh EC, Eickhoff CS, Zhang Y, Varvares MA, et al. Tumor-derived $\gamma \delta$ regulatory $T$ cells suppress innate and adaptive immunity through the induction of immunosenescence. J Immunol. 2013;190:2403-14.

82. Li J, Liu J, Mao X, Tang Q, Lu H. IL-7 receptor blockade inhibits IL-17-producing gammadelta cells and suppresses melanoma development. Inflammation. 2014;37:1444-52.

83. Welte $\mathrm{T}$, Zhang $\mathrm{XH}$. Interleukin-17 could promote breast cancer progression atseveral stages of the disease. Mediators Inflamm. 2015;2015:804347

84. Cai Y, Xue F, Fleming C, Yang J, Ding C, Ma Y, et al. Differential developmental requirement and peripheral regulation for dermal Vgamma4 and Vgamma6T17 cells in health and inflammation. Nat Commun. 2014;5:3986.

85. Bunt SK, Sinha P, Clements VK, Leips J, Ostrand-Rosenberg S. Inflammation induces myeloid-derived suppressor cells that facilitate tumor progression. J Immunol. 2006;176:284-90.

86. Rei M, Goncalves-Sousa N, Lanca T, Thompson RG, Mensurado S Balkwill FR, et al. Murine CD27(-) Vgamma6(+) gammadelta T cells producing IL-17A promote ovarian cancer growth via mobilization of protumor small peritoneal macrophages. Proc Natl Acad Sci USA. 2014:111:E3562-70.

87. Coffelt SB, Kersten K, Doornebal CW, Weiden J, Vrijland K, Hau CS, et al. IL-17-producing gammadelta T cells and neutrophils conspire to promote breast cancer metastasis. Nature. 2015;522:345-8.

88. Sabbione F, Gabelloni ML, Ernst G, Gori MS, Salamone G, Oleastro M, et al. Neutrophils suppress gammadelta T-cell function. Eur J Immunol. 2014:44:819-30

89. Kalyan S, Chandrasekaran V, Quabius ES, Lindhorst TK, Kabelitz D. Neutrophil uptake of nitrogen-bisphosphonates leads to the suppression of human peripheral blood gammadelta T cells. Cell Mol Life Sci. 2014;712:335-46.

90. Kobayashi H, Tanaka Y. Gammadelta T cell immunotherapy-a review. Pharmaceuticals (Basel). 2015;8:40-61.

91. Nakajima J, Murakawa T, Fukami T, Goto S, Kaneko T, Yoshida Y, et al. A phase I study of adoptive immunotherapy for recurrent non-small-cell lung cancer patients with autologous gammadelta T cells. Eur J Cardiothorac Surg. 2010;37:1191-7.

92. Sakamoto M, Nakajima J, Murakawa T, Fukami T, Yoshida Y, Murayama T, et al. Adoptive immunotherapy for advanced non-small cell lung cancer using zoledronate-expanded gammadelta T cells: a phase I clinical study. J Immunother. 2011;34:202-11.

93. Noguchi A, Kaneko T, Kamigaki T, Fujimoto K, Ozawa M, Saito M, et al. Zoledronate-activated Vgamma9gammadelta T cell-based immunotherapy is feasible and restores the impairment of gammadelta T cells in patients with solid tumors. Cytotherapy. 2011;13:92-7.

94. Lang JM, Kaikobad MR, Wallace M, Staab MJ, Horvath DL, Wilding $\mathrm{G}$, et al. Pilot trial of interleukin-2 and zoledronic acid to augment gammadelta $T$ cells as treatment for patients with refractory renal cell carcinoma. Cancer Immunol Immunother. 2011;60:1447-60.

95. Kobayashi H, Tanaka Y, Yagi J, Minato N, Tanabe K. Phase I/II study of adoptive transfer of gammadelta T cells in combination with zoledronic acid and IL-2 to patients with advanced renal cell carcinoma. Cancer Immunol Immunother. 2011;60:1075-84.

96. Izumi T, Kondo M, Takahashi T, Fujieda N, Kondo A, Tamura N, et al. Ex vivo characterization of gammadelta T-cell repertoire in patients after adoptive transfer of Vgamma9 Vdelta2 $T$ cells expressing the interleukin-2 receptor beta-chain and the common gamma-chain. Cytotherapy. 2013;15:481-91.

97. Kakimi K, Matsushita H, Murakawa T, Nakajima J. Gammadelta T cell therapy for the treatment of non-small cell lung cancer. Transl Lung Cancer Res. 2014;3:23-33.

98. Bennouna J, Bompas E, Neidhardt EM, Rolland F, Philip I, Galea C, et al. Phase-I study of Innacell gammadelta, an autologous cell-therapy product highly enriched in gamma9delta2 T lymphocytes, in combination with IL-2, in patients with metastatic renal cell carcinoma. Cancer Immunol Immunother. 2008;57:1599-609.

99. Wilhelm M, Smetak M, Schaefer-Eckart K, Kimmel B, Birkmann J, Einsele $\mathrm{H}$, et al. Successful adoptive transfer and in vivo expansion of haploidentical gammadelta T cells. J Transl Med. 2014;12:45.

100. Fournié J-J, Sicard $H$, Poupot $M$, Bezombes $C$, Blanc A, Romagné $F$, et al. What lessons can be learned from $\gamma \delta T$ cell-based cancer immunotherapy trials? Cell Mol Immunol. 2013;10:35-41.

101. Märten A, von Lilienfeld-Toal M, Büchler MW, Schmidt J. Soluble MIC is elevated in the serum of patients with pancreatic carcinoma diminishing $\gamma \delta$ T cell cytotoxicity. Int J Cancer. 2006;119:2359-65.

102. Lo Presti E, Toia F, Oieni S, Buccheri S, Turdo A, Mangiapane LR, et al. Squamous cell tumors recruit gammadelta T cells producing either IL17 or IFNgamma depending on the tumor stage. Cancer Immunol Res. 2017;5:397-407.

103. Kunzmann V, Smetak M, Kimmel B, Weigang-Koehler K, Goebeler M Birkmann J, et al. Tumor-promoting versus tumor-antagonizing roles of gammadelta T cells in cancer immunotherapy: results from a prospective phase I/II trial. J Immunother. 2012;35:205-13.

104. Du SH, Li Z, Chen C, Tan WK, Chi Z, Kwang TW, et al. Co-expansion of cytokine-induced killer cells and Vgamma9Vdelta2 T cells for CAR T-cell therapy. PLoS ONE. 2016;11:e0161820.

105. Chen HC, Joalland N, Bridgeman JS, Alchami FS, Jarry U, Khan MWA, et al. Synergistic targeting of breast cancer stem-like cells by human gammadelta T cells and CD8+T cells. Immunol Cell Biol. 2017. https:// doi.org/10.1038/icb.2017.21.

106. Huang $Y$, Matsumura $Y$, Hatano $S$, Noguchi N, Murakami T, Iwakura $Y$, et al. IL-21 inhibits IL-17A-producing gammadelta T-cell response after infection with Bacillus Calmette-Guerin via induction of apoptosis. Innate Immun. 2016;22:588-97.

107. Wang X, Zhao X, Feng C, Weinstein A, Xia R, Wen W, et al. IL-36gamma transforms the tumor microenvironment and promotes type 1 lymphocyte-mediated antitumor immune responses. Cancer Cell. 2015;28:296-306

108. Li W, Kubo S, Okuda A, Yamamoto H, Ueda H, Tanaka T, et al. Effect of IL-18 on expansion of gammadelta T cells stimulated by zoledronate and IL-2. J Immunother. 2010;33:287-96.

109. Li W, Yamamoto H, Kubo S, Okamura H. Modulation of innate immunity by IL-18. J Reprod Immunol. 2009:83:101-5.

110. Van Acker HH, Anguille S, Willemen $Y$, Van den Bergh JM, Berneman ZN, Lion E, et al. Interleukin-15 enhances the proliferation, stimulatory phenotype, and antitumor effector functions of human gamma delta $\mathrm{T}$ cells. J Hematol Oncol. 2016;9:101.

111. Prendergast GC, Smith C, Thomas S, Mandik-Nayak L, Laury-Kleintop $L$, Metz R, et al. Indoleamine 2,3-dioxygenase pathways of pathogenic inflammation and immune escape in cancer. Cancer Immunol Immunother 2014:63.721-35

112. Gomes AQ, Correia DV, Grosso AR, Lanca T, Ferreira C, Lacerda JF, et al. Identification of a panel of ten cell surface protein antigens associated with immunotargeting of leukemias and lymphomas by peripheral blood gammadelta T cells. Haematologica. 2010;95:1397-404.

113. Mondragon L, Kroemer G, Galluzzi L. Immunosuppressive gammadelta T cells foster pancreatic carcinogenesis. Oncoimmunology. 2016:5:e1237328.

114. Li Z, Li N, Li F, Zhou Z, Sang J, Chen Y, et al. Immune checkpoint proteins PD-1 and TIM-3 are both highly expressed in liver tissues and correlate with their gene polymorphisms in patients with HBV-related hepatocellular carcinoma. Medicine. 2016;95:e5749. 
115. He Y, Yu H, Rozeboom L, Rivard CJ, Ellison K, Dziadziuszko R, et al. LAG-3 protein expression in non-small cell lung cancer and its relationship with PD-1/PD-L1 and tumor-infiltrating lymphocytes. J Thorac Oncol. 2017;12:814-23.
116. Lines JL, Pantazi E, Mak J, Sempere LF, Wang L, O'Connell S, et al. VISTA is an immune checkpoint molecule for human T cells. Cancer Res. 2014;74:1924-32.
Submit your next manuscript to BioMed Central and we will help you at every step:

- We accept pre-submission inquiries

- Our selector tool helps you to find the most relevant journal

- We provide round the clock customer support

- Convenient online submission

- Thorough peer review

- Inclusion in PubMed and all major indexing services

- Maximum visibility for your research

Submit your manuscript at www.biomedcentral.com/submit
() Biomed Central 